\title{
Memory loss from a subcortical white matter infarct
}

\author{
CAROL A KOOISTRA, KENNETH M HEILMAN \\ From the Department of Neurology, College of Medicine, University of Florida, and the Research Service, \\ Veterans Administration Medical Center, Gainesville, FL, USA
}

SUMMARY Clinical disorders of memory are believed to occur from the dysfunction of either the mesial temporal lobe, the mesial thalamus, or the basal forebrain. Fibre tract damage at the level of the fornix has only inconsistently produced amnesia. A patient is reported who suffered a cerebrovascular accident involving the posterior limb of the left internal capsule that resulted in a persistent and severe disorder of verbal memory. The inferior extent of the lesion effectively disconnected the mesial thalamus from the amygdala and the frontal cortex by disrupting the ventral amygdalofugal and thalamic-frontal pathways as they course through the diencephalon. This case demonstrates that an isolated lesion may cause memory loss without involvement of traditional structures associated with memory and may explain memory disturbances in other white matter disease such as multiple sclerosis and lacunar state.

Memory loss is currently believed to reflect grey matter damage of either the mesial temporal lobe ${ }^{1-4}$ the mesial thalamus, ${ }^{5-9}$ or the basal forebrain. ${ }^{1011}$ Cerebrovascular accidents resulting in memory dysfunction may occur in any of these three regions. ${ }^{37-91213}$ In contrast, amnesia from white matter damage is unusual and when present is usually related to fornix lesions. ${ }^{14-19}$

We observed a patient, however, who developed a severe verbal amnesia from an infarct of the posterior limb of the internal capsule. Aside from its obvious sparing of the usual structures involved in memory, the lesion was also atypical by its apparent limitation to the white matter pathways of the diencephalon.

\section{Case report}

A 69 year old, right-handed, high school educated gas station supervisor was in good health until the acute onset of a right hemiparesis associated with dysarthria and mild expressive difficulties. His symptoms improved after 2 hours, only to recur 30 minutes later, at which time continuous intravenous heparin was begun. His deficits fluctuated over the next 36 hours before becoming permanent. On the 10th

Address for reprint requests: Carol A. Kooistra, M.D., 145 Dillon Drive, Spartanburg, S.C. 29302, USA

Received 20 February 1987 and in revised form 21 September 1987. Accepted 22 September 1987 day of his illness the patient was transferred to Shands Teaching Hospital at the University of Florida for further evaluation.

Examination at that time showed the patient to be awake, alert, attentive and fully oriented. He was able to repeat four numbers forward, could not recall any of three objects after 3 minutes, but was able to remember recent presidents. Spontaneous speech was grammatically correct with mild hesitancy on initiation of sentences and a tendency towards echolalia. Repetition, naming, reading and writing were all preserved. Verbal comprehension was mildly impaired only when dependent upon understanding complex syntactic relationships. Finger naming, right/left orientation and calculations were normal. Visual-spatial testing of spontaneously drawn and copied figures was normal. There was no neglect and no difficulty with either graphaesthesia or stereognosia. The remainder of his neurological examination demonstrated a moderate right hemiparesis in a pyramidal distribution with concomitant hyperreflexia and extensor plantar response. Neuropsychological assessment included Form 1 of the Wechsler Memory Scale. Despite scoring nearly flawlessly on the personal information (6/6) and orientation (4/5) subtests, the patient only recalled $4 / 24$ and $2 / 22$ memories from the logical memory subtest (about 2 SD below that expected for his intelligence and age). ${ }^{20}$ Paired associate testing yielded a score of $4 / 21$ (all easy associations), which falls more than 3 SD below the mean. ${ }^{20}$ In contrast, nonverbal memory function was less affected, as shown by his visual reproduction subtest score (4/14), only I SD below mean. His memory quotient was calculated as 79 .

A computed tomography (CT) scan of the head 14 days after onset of symptoms revealed an area of lucency 


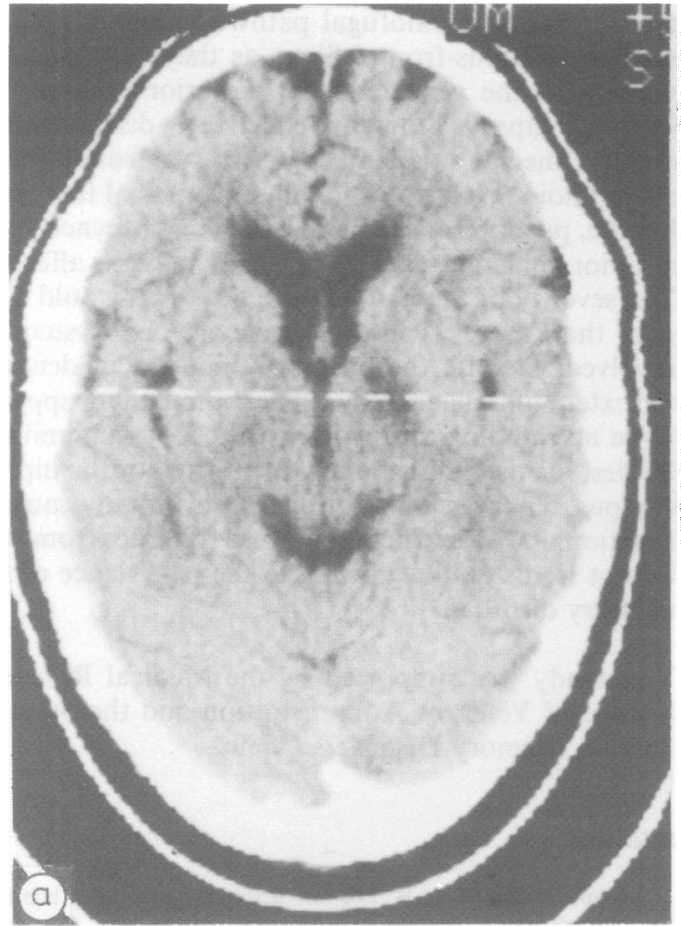

occupying the posterior limb and genu of the left internal capsule (fig). Coronal reconstruction demonstrated the inferior aspect of the lesion to extend within the white matter to just above the suprasellar cistern (fig). The arterial distribution of the presumed thrombotic infarct was felt to best fit that of the anterior choroidal artery. ${ }^{21}$

Over the following weeks, the patient demonstrated mild improvement in motor deficits; however, two years after discharge he remains significantly amnestic, incapable of recalling any of three objects after three minutes.

\section{Discussion}

Amnesia has not been previously recognised as a sequela of damage to the internal capsule. Therefore, the presence of severe memory deficits in this case may be related to damage to some additional diencephalic structure(s), with sparing of the dorsal medial thalamus, hippocampal formation, and basal forebrain.

Recent experimental work in memory has emphasised two separate but parallel anatomic systems: the hippocampal and the amygdaloid. The former is essentially composed of those pathways described by Papez $^{22}$ in which hippocampal efferents travel through the fornix to reach directly (postcommissurally) ${ }^{23}$ and indirectly (via the mammillary bodies and mammillothalamic tract) the anterior nucleus of the thalamus, which then subsequently

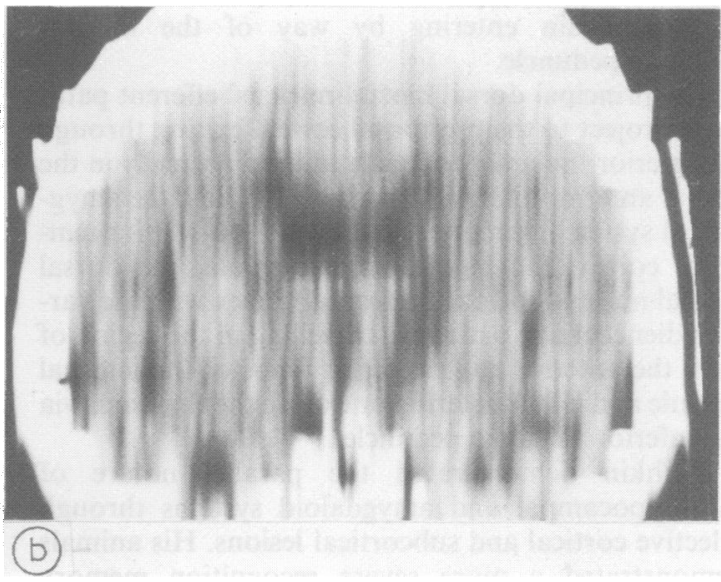

Fig (a) CT scan showing lucency in left posterior internal capsule. (b) coronal CT scan, reconstructed, showing lucency in internal capsule.

projects to the cingulate gyrus through the lateral thalamic radiations and post-commissural fornix. ${ }^{22} 24$

The amygdaloid system was delineated by Yakovlev $^{23}$ and brought to prominence by Horel's temporal stem theory of amnesia. ${ }^{24}$ This system's targets again lie within the diencephalon and are reached by either the stria terminalis or ventral amygdalofugal pathways. The stria terminalis lies in the lateral wall of the temporal horn and body of the lateral ventricle, arching superiorly and anteriorly to cross the anterior limb of the internal capsule and anterior commissure and connecting with the hypothamalus, nucleus accumbens and anterior pole of the thalamus. $^{2526}$

The ventral amygdalofugal pathway consists of two components. Both originate from the basolateral amygdala and travel anteriorly and medially through the albal stalk of the temporal lobe to enter the inferior diencephalon. One component continues rostrally to the septal region as the diagonal band of Broca, additionally sending some fibres to the dorsal medial thalamus via the inferior thalamic peduncle. ${ }^{25}$ The second component forms the ansa peduncularis, which courses medially, lying ventral to the ansa lenticularis and posterior limb of the internal capsule, and ultimately reaches the hypothalamus, whereupon the fibres turn superiorly and posteriorly to terminate in the magnocellular portion of the dorsal medial 
nucleus, again entering by way of the inferior thalamic peduncle.

The principal dorsal medial nucleus' efferent pathways project to the prefrontal cortex, exiting through the inferior thalamic peduncle to head rostrally in the lateral anterior internal capsule. ${ }^{27} 28$ Thus, the amygdaloid system interconnects the anterior inferior temporal cortex, the basolateral amygdala, the dorsal medial nucleus and the prefrontal cortex with the various diencephalic pathways travelling in the region of both the anterior and posterior limbs of the internal capsule and either entering or exiting the thalamus via the inferior thalamic peduncle.

Mishkin demonstrated the parallel nature of the hippocampal and amygdaloid systems through selective cortical and subcortical lesions. His animals demonstrated a more severe recognition memory deficit with combined destruction of amygdala and hippocampus than with an isolated lesion of either structure. ${ }^{29}$ Similar results were obtained with single and combined lesions of the anterior and dorsal medial nuclei of the thalamus, ${ }^{3031}$ the fornix and stria terminalis, ${ }^{32}$ the hippocampus and stria terminalis, ${ }^{18}$ and the fornix and amygdala. ${ }^{33}$

Recently, the basal nucleus of Meynert has emerged as a contributor to mnemonic function. The cells of the basal nucleus do not occupy a discrete area of the substantia innominata, but rather can be found adjacent to the septal region, as well as within the ansa lenticularis, the ansa peduncularis, the inferior thalamic peduncle, the internal capsule, the medial forebrain bundle, the anterior commissure and the medullary lamina of the globus pallidus. ${ }^{34}$ Afferents originate predominantly from the allocortex, the septal region, the nucleus accumbens and the hypothalamus, ${ }^{35}$ with anterior nucleus projecting to mesial cortex via the fornix and the cingulum and the posterior nucleus projecting to the dorsolateral cortex. ${ }^{36}$

Aside from Mishkin's work involving fibre tract lesions, other experimental support exists for diencephalic white matter damage causing memory deficits. Skinner and Lindsley placed cryogenic probes within the inferior thalamic peduncle of cats and produced deficits in tasks of bar pressing and single alternation. ${ }^{37}$ Additionally, Mair, Warrington, and Weiskrant $\mathrm{z}^{38}$ identified a small zone of damaged diencephalon in patients with Korsakoff's disease, which they felt disconnected structures in the temporal lobe from areas in the frontal cortex. Considering the extensive network of pathways needed to coordinate mnemonic function, a variety of white matter lesions could potentially produce amnesia and may form the basis of memory loss associated with both multiple sclerosis and multi-infarct dementia.

The infarct reported here appears to extend sufficiently inferiorly and anteriorly to have damaged the ventral amygdalofugal pathways and the dorsal medial thalamus-frontal fibres as they course in the vicinity of the genu and the posterior limb of the internal capsule, thereby effectively disconnecting dorsal medial thalamus from prefrontal and amygdaloid areas. Additionally, the medial forebrain bundle, portions of the basal nucleus of Meynert, and anterior thalamic nucleus efferents may be affected. The severity of the patient's memory loss would suggest that more than one structure or system is involved. Despite the problems inherent in defining the extent of ischaemia by CT scanning, there appears to be no radiological involvement of the mammillary bodies, the medial thalamus, the fornix, or the hippocampus. The possibility of diaschisis initially causing functional disturbances in areas remote from the infarct seems unlikely owing to the persistence of the memory disorder.

This study was supported by the Medical Research Service of Veterans Administration and the State of Florida Memory Disorders Clinic.

\section{References}

1 Scoville WB, Milner B. Loss of recent memory after bilateral hippocampal lesions. $J$ Neurol Neurosurg Psychiatry 1957;20:11-21.

2 Drachman DA, Adams RD. Herpes simplex and acute inclusionbody encephalitis. Arch Neurol 1962;7:45-63.

3 Benson DF, Marsden CD, Meadows JC. The amnesic syndrome of posterior cerebral artery occlusion. Acta Neurol Scand 1974;50:133-45.

4 Cummings JL, Tomiyasu U, Read S, Benson DF. Amnesia with hippocampal lesions after cardiopulmonary arrest. Neurology 1984;34:679-81.

5 Victor M, Adams RD, Collins GH. The Wernicke-Korsakoff Syndrome. Oxford: Blackwell, 1971.

6 Markowitsch HJ. Thalamic mediodorsal nucleus and memory: a critical evaluation of studies in animals and man. Neurosci Biobehav Rev 1982;6:351-80.

7 Speedie LJ, Heilman KJ. Amnestic disturbance following infarction of the left dorsomedial nucleus of the thalamus. Neuropsychologia 1982;20:597-604.

8 Choi D, Sudarsky L, Schachter S, Biber M, Burke P. Medial thalamic hemorrhage with amnesia. Arch Neurol 1983;40: 611-3.

9 Graff-Radford NR, Eslinger PJ, Damasio AR, Yamada T. Nonhemorrhagic infarction of the thalamus: behavioral, anatomic and physiologic correlates. Neurology 1984;34:14-23.

10 Rogers JD, Brogan D, Mirra SS. The nucleus basalis of Meynert in neurological disease: a quantitative morphological study. Ann Neurol 1985;17:163-70.

11 Whitehouse PJ, Price DL, Clark AW, Coyle JT, Delong MR. Alzheimer's disease: evidence for selective loss of cholinergic neurons in the nucleus basalis. Ann Neurol 1981;10:122-6.

12 Damasio AR, Damasio $H$. The anatomic basis of pure alexia. Neurology 1983;33:1573-83.

13 Damasio AR, Graff-Radford NR, Eslinger PJ, Damasio H, Kassell N. Amnesia following basal forebrain lesions. Arch Neurol 1985;42:263-71.

14 Gaffan D. Recognition impaired and association intact in the memory of monkeys after transection of the fornix. J Comp 
Physiol Psychol 1974;86:1100-9.

15 Woolsey RM, Nelson JS. Asymptomatic destruction of the fornix in man. Arch Neurol 1975;32:566-8.

16 Owen MJ, Butler SR. Amnesia after transection of the fornix in monkeys: long-term memory impaired, short-term memory intact. Behav Brain Res 1981;3:115-23.

17 Mahut H, Zola-Morgan S, Moss M. Hippocampal resections impair associative learning and recognition memory in the monkey. J Neurosci 1982;2:1214-29.

18 Mishkin M. A memory system in the monkey. Philos Trans $R$ Soc Lond (Biol) 1982;298:85-95.

19 Heilman KM, Sypert GW. Korsakoff's syndrome resulting from bilateral fornix lesions. Neurology 1977;27:490-3.

20 Wechsler DA. A standardized memory scale for clinical use. $J$ Psychol 1945;19:87-95.

21 Robertson RT, Kaitz SS. Thalamic connections with limbic cortex I. Thalamocortical projections. J Comp Neurol 1981;195:501-25.

22 Papez JW. A proposed mechanism of emotion. AMA Arch Neurol Psychiatry 1937;38:725-43.

23 Yakovlev PI. Motility, behavior, and the brain. Stereodynamic organization and neural coordinates of behavior. J Nerv Ment Dis 1948;107:313-35.

24 Horel JA. The neuroanatomy of amnesia: a critique of the hippocampal memory hypothesis. Brain 1978;101:403-45.

25 Klinger J, Gloor P. The connections of the amygdala and of the anterior temporal cortex in the human brain. J Comp Neurol 1960;115:33-69.

26 Aggleton JP, Mishkin M. Projections of the amygdala to the thalamus in the cynomolgus monkey. J Comp Neurol 1984;222:56-68.

27 Krettek JE, Price JL. The cortical projections of the mediodorsal nucleus and adjacent thalamic nuclei in the rat. J Comp Neurol 1977;171:157-92.

28 Scheibel ME, Scheibel AB. Structural organization of the nonspecific thalamic nuclei and their projection toward cortex. Brain Res 1967;6:60-94.

29 Mishkin M. Memory in monkeys severely impaired by combined but not by separate removal of amygdala and hippocampus. Nature 1978;273:297-8.

30 Aggleton JP, Mishkin M. Visual recognition impairment following medial thalamic lesions in monkeys. Neuropsychologia 1983;21:189-97.

31 Aggleton JP, Mishkin M. Memory impairments following restricted medial thalamic lesions in monkeys. Exp Brain Res 1983;52:199-209.

32 Bachevalier J, Parkinson JK, Aggleton JP, Mishkin M. Severe recognition impairment after combined but not separate transection of the fornix and the amygdalofugal pathways. Soc Neurosci Abstr 1982;8:23.

33 Mishkin M, Saunders RC. Degree of memory impairment in monkeys related to amount of conjoint damage to amygdaloid and hippocampal systems. Soc Neurosci Abstr 1979;5:320.

34 Mesulam M-M, Mufson EJ, Levey AI, Wainer BH. Cholinergic innervation of cortex by the basal forebrain: cytochemistry and cortical connections of the septal area, diagonal band nuclei, nucleus basalis (substantia innominata), and hypothalamus in the rhesus monkey. J Comp Neurol 1983;214:170-97.

35 Mesulam M-M, Mufson EJ. Neural inputs into the nucleus basalis of the substantia innominata (Ch 4$)$ in the rhesus monkey. Brain 1984;107:253-74.

36 Divac I. Magnocellular nuclei of the basal forebrain project to neocortex, brainstem, and olfactory bulb. Review of some functional correlates. Brain Res 1975;93:385-98.

37 Skinner JE, Lindsley DB. Electrophysiological and behavioural effects of blockade of the nonspecific thalamo-cortical system. Brain Res 1967;6:95-118.

38 Mair WGP, Warrington EK, Weiskrantz L. Memory disorder in Korsakoff's psychosis: a neuropathological and neuropsychological investigation of two cases. Brain 1979;102:749-83. 